\title{
An Online-Education System Budgeting Framework ---Based on IT-Governance Model
}

\author{
Linlin LI \& Hongying MA \\ Shenyang Open University, Shenyang, China
}

\begin{abstract}
Proposed a budget decision framework for online education systems from the view of ITGovernance theory, based on investigations on 11 actual cases. Main features of the model are: (A) identifying performance from 5 domains of common IT-Governance models (B) assessing project risk and benefit by a nonlinear evaluation algorithm (C) evaluating the budget decision on the inputs of risk, benefit and investment. The model has been applied in several projects. The paper discussed the models in the framework, and compared the evaluation results outputted by the framework and that by experts.
\end{abstract}

KEYWORDS: Online Education, Inverstment Mangement, IT Governance

\section{RESEARCH BACKGROUND}

As the rapid growth of e-education industry in the recent years, online learning plays a more and more important role in modern education. To resolve the problem and improve the effect of e-education project management, we traced several typical eeducation projects, and proposed a solution framework based on empirical analysis.

We have examined 11 various E-Learning projects, and table 1 shows the distribution of the sample. The investigating methods include fieldinquiry and questionnaire, snapshot review in production system, data integration test on production system[5], walk-through test in function line, and Delphi review method.

Table 1. The investigation sample distribution

\begin{tabular}{|c|c|c|c|}
\hline \multirow{2}{*}{$\begin{array}{c}\text { Business } \\
\text { Category }\end{array}$} & $\begin{array}{c}\text { Online } \\
\text { Learning }\end{array}$ & $\begin{array}{c}\text { Resource } \\
\text { Database }\end{array}$ & $\begin{array}{c}\text { Education } \\
\text { Management }\end{array}$ \\
\cline { 2 - 4 } & 3 & 2 & 2 \\
\hline $\begin{array}{c}\text { Budget Scale } \\
\text { (RMB 1,000) }\end{array}$ & Less than 100 & $100-2,000$ & More than 2,000 \\
\cline { 2 - 4 } & 3 & 3 & 1 \\
\hline $\begin{array}{c}\text { Project } \\
\text { Category }\end{array}$ & Wholly New & Upgraded & $\begin{array}{c}\text { Fundamental } \\
\text { Infrastructure }\end{array}$ \\
\cline { 2 - 4 } & 4 & 1 & 2 \\
\hline
\end{tabular}

We proposed a framework to solve the problem, which is, to build up an IT-Governance performance evaluation model, and apply it as early as in the budgeting phase for e-education project. The framework consists of two models: a performance evaluation model and a budget decision model[6]. The former one is a quantitative scoring model and has been applied in IT-Governance performance evaluation works in some colleges. The latter one is a theoretical model to support budgeting decision, and has been accepted by related departments.

\section{BRIEF INTRODUCTION OF EXISTING RESEARCHES}

IT Governance is one of the most popular topics in today's IT management research. The final goal of IT-Governance is to keep IT systems in organizations to support or enable business objectives, and to mitigate business risks associated with IT implementation [1][2]. Major IT-Governance models includes COBIT [3] and ISO-17799 [4], both of which focus on domains such as strategic planning, performance evaluation, assets-acquirement and risk management.

Performance evaluation and related budgeting method has been applied into management area for more than 50 years in developed countries such as USA and UK. From 1990s, information system projects have been a huge investment for these countries, and required an advanced special performance based budgeting framework to meet the complexity and specialization of information systems. In 2002, USA government proposed the "Performance Reference Model (PRM)" as a part of the "Federal Enterprise Architecture (FEA)", which can be used in project performance evaluation in collaboration with the form A300 and the other models in FEA [7]. This model provides a series of 
general indicators, which can be adapted to individual forms by each evaluated department, include education institutions. This model has been applied in federal budgeting decision since BY 2004, and obviously improved the manage efficiency. In China, such researches are few. Peng Xizheng discussed the basic concept of performance evaluation in ref [8]. Mi Hong proposed a preassessment index system in ref [9].

\section{THE PERFORMANCE EVALUATION MODEL}

\subsection{The indicator system}

To reflect the whole IT-Governance performance of an e-education system, the performance evaluation model contains 14 groups of indicators (43 detailed indicators totally) of 5 domains:

Education quality domain. Education quality is a direct performance factor as the final output of eeducation system. To contain all key aspects on service chain in various systems, this domain includes "Education Effect and Service Delivery Speed", "Student Convenient", and "Service Focus".

Technology domain. Technology is the inner driven power of e-education system. The characters of technology can disclosure many potential performance trends which can not be shown by service domain alone. Here we divided the technology indicators into "Architecture", "Standard Compliance", "Security", "Reliability", "Extendibility".

System life domain. Sustainability focused on the long-term strategic performance. This domain consists of two environment factors that will influence the projects: "Organizational Environment" and "Law Environment".

Invest benefit domain. Compare between the cost and the benefit can directly reflect the efficiency of investment. Since the main purpose of most eeducation systems is to gain social benefit more than economic benefit, we transform most cost and benefit indicator into non-monetary form, such as "Reduction of Education Process", "New Mode of Teaching and Study".

Reuse-ability domain. The ability to reuse a system in different environments is very important to a large-scale government. Since most regular transactions in different departments are similar, developed a powerful system and reused it into all needed departments will obviously decrease the redundancy constructing and save the total budget. So we designed three important indicators to examine the reuse-ability performance: "Technology Reuse", "Function Reuse" and "Business Mode Reuse”.

\subsection{The evaluation algorithm}

\subsubsection{Nondimensionalization of indicators}

By analyzing the investigation data, we found many of the indicators' levels belong to non-linear distributing. Table 2 shows an example. In this sample, we can hardly reflect the difference among each project with a linear nondimensionalization method such as weighted mean method. If we set $41 \%$ as the lower limit, the better systems (4 in sample) whose compliance rate greater than $91 \%$ will have the same score. Otherwise if we set $91 \%$ as the lower limit, then we are not able to compare the systems whose rate less than $91 \%$. So in both cases, the evaluation score will be useless.

Table 2. The sample data of indicator "Compliance With Promised Response Time"

\begin{tabular}{|c|c|c|c|c|c|c|c|}
\hline $\begin{array}{c}\text { Compliance } \\
\text { rate }\end{array}$ & $0 \%-$ & $41 \%-$ & $51 \%-$ & $61 \%-$ & $71 \%-$ & $81 \%-$ & $91 \%-$ \\
90 & $50 \%$ & $60 \%$ & $70 \%$ & $80 \%$ & $90 \%$ & $100 \%$ \\
\hline Sample count & 0 & 1 & 1 & 0 & 1 & 1 & 11 \\
\hline
\end{tabular}

For the reason, we use a fuzzy nondimensionalization algorithm (formula 1) which can clearly reflect the non-linear distribution of indicators. Figure 1 explains that.

$R_{j}(x)= \begin{cases}0.5+0.5 \sin \left[\frac{\pi}{x_{j \max }-x_{j \min }}\left(x_{j}-\frac{x_{j \max }+x_{j \min }}{2}\right)\right], & x_{j \min }<x_{j}<x_{j m x} \\ 0, & x_{j} \geq x_{j \max } \text { 或 } x_{j} \leq x_{j \text { min }}\end{cases}$

$x_{j}$ is the original value of the indicator $x, R_{j}(x)$ is the dimensionless value, $x_{j \max }$ is the reasonable upper limit, $x_{j \min }$ is the reasonable lower limit. This formula has been used in the performance evaluation of supply-chain system successfully (ref. [8]), and so did in our investigation.

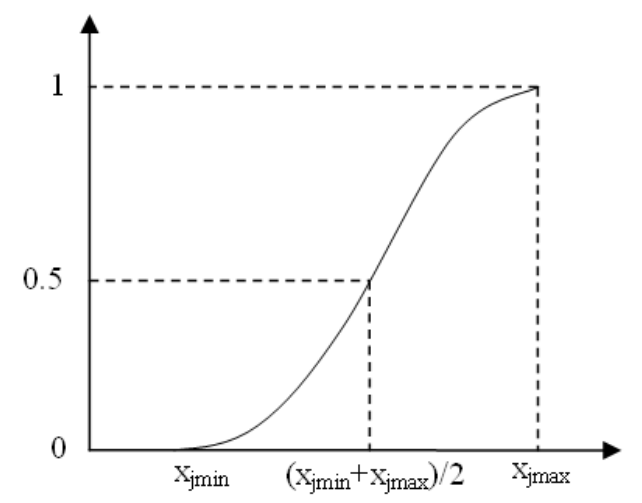

Figure 1. Fuzzy nondimensionalization algorithm

\subsubsection{Evaluation algorithm}

The evaluation algorithm will integrate all the dimensionless indicator values into one integrated score for understanding the whole performance of one project or comparing the performances among different projects.

The first step is to integrate indicator values in 
each domain by weighted mean method. Since the non-linear problem has been solved by formula (1), the weighted mean method can work well in this step. After this step, we can get a vector of scores of five domains. Because of the obvious orthogonality of $p_{n}$, we need an algorithm which can integrate the five scores reasonably.

Suppose $P$ as the integrated score, $p_{n}(n=1, \ldots, 5)$ as the vector of scores of domains, $R$ as the failure risk of whole system, $r_{n}(n=1,2,3,4,5)$ as the failure risk of each domain, we can get hypothesis below:

Hypothesis 1: $P$ positively correlate with ${ }^{p_{n}}$, and negatively correlate with $R$.

Hypothesis 2: ${ }^{p_{n}}$ negatively correlate with ${ }^{r_{n}}$.

Hypothesis 3: The general risk control formula $R=1-\prod\left(1-r_{n}\right)$ is also suitable for $R$ and $r_{n}$.

Hypothesis1 and 2 can be accepted because of the general definition of performance and risk. Hypothesis 3 has been accepted in IT manage, control and audit for many years, which make it acceptable here too. Then we get formula (2).

$R=1-\prod\left(1-r_{n}\right), \quad R=f(P), \quad r_{n}=g\left(p_{n}\right), \quad n=(1 \ldots .5)$

According to the normal risk control model $r=1-c$, set $f(P)=1-P+\varepsilon, g\left(p_{n}\right)=1-p_{n}+\eta$, then $P=\prod\left(p_{n}-\eta\right)+\varepsilon$. Formulate $P$ into $[0,1]$, and we can get the final evaluation formula (3):

$$
P=\left[\prod\left(p_{n}-\eta\right)+\eta^{5}\right] /\left[(1-\eta)^{5}+\eta^{5}\right] \quad, \quad n=(1, \ldots, 5)
$$

\subsubsection{Verification of the evaluation model}

We selected 5 various e-education projects as the sample to verify the evaluation model. Table 3 shows the basic attributes of the verify sample.

Table 3. The verify sample

\begin{tabular}{|c|c|c|c|}
\hline \multirow{2}{*}{$\begin{array}{c}\text { Business } \\
\text { Category }\end{array}$} & $\begin{array}{c}\text { Online } \\
\text { Learning }\end{array}$ & $\begin{array}{c}\text { Resource } \\
\text { Database }\end{array}$ & $\begin{array}{c}\text { Education } \\
\text { Management }\end{array}$ \\
\cline { 2 - 4 } & 2 & 2 & 1 \\
\hline $\begin{array}{c}\text { Budget Scale } \\
\text { (RMB 1,000) }\end{array}$ & Less than 100 & $100-2,000$ & More than 2,000 \\
\cline { 2 - 4 } & 2 & 2 & 1 \\
\hline
\end{tabular}

We first collected the original scores of detailed indicators by field examination and questionnaires, and then calculated the integrated scores using the model. Considering the lack of experience in first time use, we set the risk adjust factor $\eta$ equals 0.25 , and set the weights using AHP method. We also asked a group of professionals and experienced administrators in government to evaluate these projects independently. We compared the professional-group's evaluation results with that of our model. The Pearson's correlation coefficient is 0.761 , and the significance level is less than 0.01 .

\section{THE BUDGETING DECISION MODEL}

When examine a budget application about eeducation project, we can use the budgeting decision model based on performance scores to assess the possibility to success, and decide whether to approve the application. Figure 2 shows the basic structure of the model.

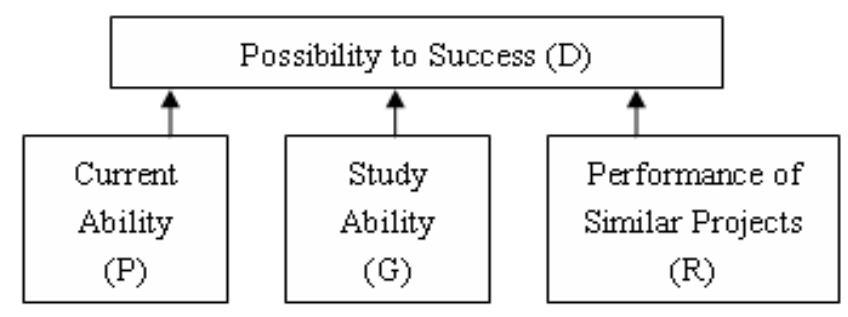

Figure 2. The Budgeting Decision Model

In this model, we supposed the possibility as a function depends on three main variables:

(1) $P$ - Current ability to run an e-education project of the applicant. This ability can be assessed using its historic performance scores of other projects. The formula is $P=\sum_{t=1}^{n}\left[t \sum_{j=1}^{m_{t}} S_{t j} \cdot d_{t j} /\left(n ! m_{t}\right)\right]$, in which $n$ is the count of recorded years, $m_{t}$ is the evaluated projects count in year $t, S_{t j}$ is the score of one project in year $t$, and $d_{t j}$ is the important weight to the project.

(2) $S$ - Study ability on e-education constructing of the applicant. It reflects the future trend of the applicant, and $G=\sum_{i=1}^{n}\left(i-\frac{1+n}{2}\right) \cdot\left(A_{i}-\frac{1}{n} \sum_{j=1}^{n} A_{j}\right) /\left[\sum_{i=1}^{n} i^{2}-n \cdot \frac{(1+n)^{2}}{4}\right], A_{i}=\sum_{j=1}^{m} S_{i j} / m \quad, \quad$ in which $A_{i}$ is the average level of scores in year $i$, and other parameters are the same as fore formula.

(3) $R$ - The performances of similar projects run by anybody. This item can give a reference to forecast the future performance of the application project, and can be easily gotten by using weighted mean method on all similar projects' performance scores in database.

Since there has no historic performance scores by now yet, we can only suppose the final decision function as the simplest theoretical form $D=a \sqrt{b(P+G) \cdot R}+c$, in which $a, b$ and $c$ are all adjust factors.

The model has been applied in some administrator departments in Liaoning Open University, and we will keep on upgrading the model as new data are collected. 


\section{CONCLUSION}

Based on the empirical study on actual cases, we proposed a budgeting framework for online education project management in China. The core of the framework is an IT-Governance performance model, covering main domains of general online education business. The framework has been proved practical and objective, which has been proven by trial in some colleges. However, the budget decision model has to be improved and verified in future because of the lack of historic data now. We will keep the research go on.

\section{REFERENCES}

[1] P.L. Bowen, M.-Y.D. Cheung, F.H. Rohde, Enhancing IT governance practices: a model and case study of an organization's efforts International Journal of Accounting Information Systems, 8 (3) (2007), pp. 191-221.
[2] A.S. Sohal, P. Fitzpatrick IT governance and management in large Australian organisations International Journal of Production Economics, 75 (1/2) (2002), pp. 97-112.

[3] Control objectives for information and related technologies (COBIT). 4rd ed. USA: IT Governance Institute; 2006.

[4] ISO/IEC 17799, Information technology e code of practice for informationsecurity management. Switzerland: International Organization for Standardization (ISO); 2000.

[5] Joe Lin, Charley Ho, Wasim Sadiq and Maria E. Orlowska, "Using Workflow Technology to Manage Flexible eLearning Services", Educational Technology \& Society 5(4) 2002.

[6] Gardner, L.; Sheridan, D.; White, D., "Computer Supported Learning - A Large-Scale, Web-Based Learning and Assessment System to Support.

[7] OMB USA. Federal Enterprise Architecture. 2005:1-17.

[8] Peng Xizheng. A Discussion on E-education Performance Evaluation Framework. Chinese Informatization, 2005 6.27. (in Chinese)

[9] Mi Hong. Studies on Index System and Comprehensive Evaluation of Pre-assessment in E-education Item. Journal of Xiamen University, 2004(8):279-283. (in Chinese) 